\title{
ALGUNOS ASPECTOS DE LA ACCIÓN SANITARIA DURANTE EL PROTECTORADO DE ESPAÑA EN MARRUECOS
}

\author{
Abdelmalik El Barkani Abdelkader ${ }^{1}$ \\ Doctor en Medicina y Cirugía, Neurocirujano
}

Resumen: En este artículo se realiza un pequeño repaso de la acción sanitaria de España en la zona norte de Marruecos durante el Protectorado. Se aborda el origen y la organización del Protectorado, tanto política como administrativamente, para a continuación referirse a la situación sanitaria en Marruecos antes del inicio de la acción protectora. Posteriormente se analiza la organización sanitaria que España creó en esta zona y fundamentalmente en dos secciones: Los servicios de la Dirección General y las luchas y campañas sanitarias. El artículo finaliza recordando cuáles fueron los resultados obtenidos y cuál la situación médica y sanitaria de Marruecos al independizarse este país en 1956.

Palabras clave: Protectorado de España en Marruecos, Servicios sanitarios, Organización sanitaria, campañas médicas, medicina española, medicina tradicional.

Summary: This article presents a brief review of what has been the sanitary action that Spain has carried out in the northern region of Morocco during the Protectorate. It deals with the origin and the Protectorate's organization, both political and administratively, afterwards to refer to the situation in Morocco before the beginning of the protective action. Subsequently, it analyses the sanitary organisation Spain created within this area and fundamentally within these two sections: Services of general management and sanitary campaigns. In conclusion, the article records the final results and what the medically sanitary situation was when they became independent in 1956.

Keywords: Spanish Protectorate in Morocco, Health /sanitary services, sanitary organization, medical campaigns, Spanish medicine, Traditional medicine.

${ }^{1}$ Académico Correspondiente de la Real Academia de Medicina y Cirugía de Andalucía Oriental. Académico de Honor de la Academia Española de Estudios Históricos de Estomatología y Odontología. 


\section{Origen y organización del Protectorado}

\section{Origen y organización territorial}

A finales del siglo XIX, el sultanato de Marruecos vivía envuelto en una anarquía e inestabilidad política. Las rivalidades entre Francia, Inglaterra y Alemania, tras la Conferencia de Algeciras en 1906 y tras la firma del Tratado hispano-francés en 1912 (Tratado de Madrid), dieron como resultado la división de Marruecos en dos protectorados: uno al sur, de mayor extensión, adjudicado a Francia; el otro, al norte, en las montañas del Rif, más pobre y reducido, adjudicado a España.

Mientras que la zona francesa, al sur, era la más rica con importantes ciudades comerciales como Oujda, Taza, Fez, Meknès, Rabat, Casablanca y Marrakech, la zona española, al norte, era un erial montañoso, secularmente indómito a la autoridad del Sultán, en la que tan solo Tetuán y Larache eran ciudades importantes, por estar Tánger sometida a una jurisdicción internacional; el resto eran cábilas con míseros poblados y pobres asentamientos, agrupados en cuatro grandes grupos de la familia bereber.

En 1918 el Protectorado estaba dividido en una zona occidental y otra oriental, teniendo como centros las comandancias militares de Melilla y Ceuta. Fue a partir de 1927 cuando la Alta Comisaría empezó a organizar el territorio en regiones, que no existían previamente como entidades administrativas. En 1935, el servicio de Intervenciones dividió el territorio en cinco zonas [1]: el Lucus, capital Larache, Yebala, capital Tetuán, Gomora, capital Chaouen, el Kert, capital Villa Nador y el Rif, capital Villa Sanjurjo.

El territorio más extenso era el Kert, con algo más de $6.000 \mathrm{Km}^{2} \mathrm{de}$ extensión y a su vez la región cercana a Melilla.

Así esta división se mantuvo hasta el final del Protectorado.

\section{Organización administrativa}

Con el objeto de cumplir los compromisos adquiridos en el convenio hispano-francés del 27 de noviembre de 1912, los gobiernos españoles tuvie- 
ron que organizar un entramado político administrativo, de carácter dual, que incluyera una renovada administración marroquí (el Majzén Jalifiano) y otra española (la Alta Comisaría) que auxiliara e interviniera a las autoridades marroquíes.

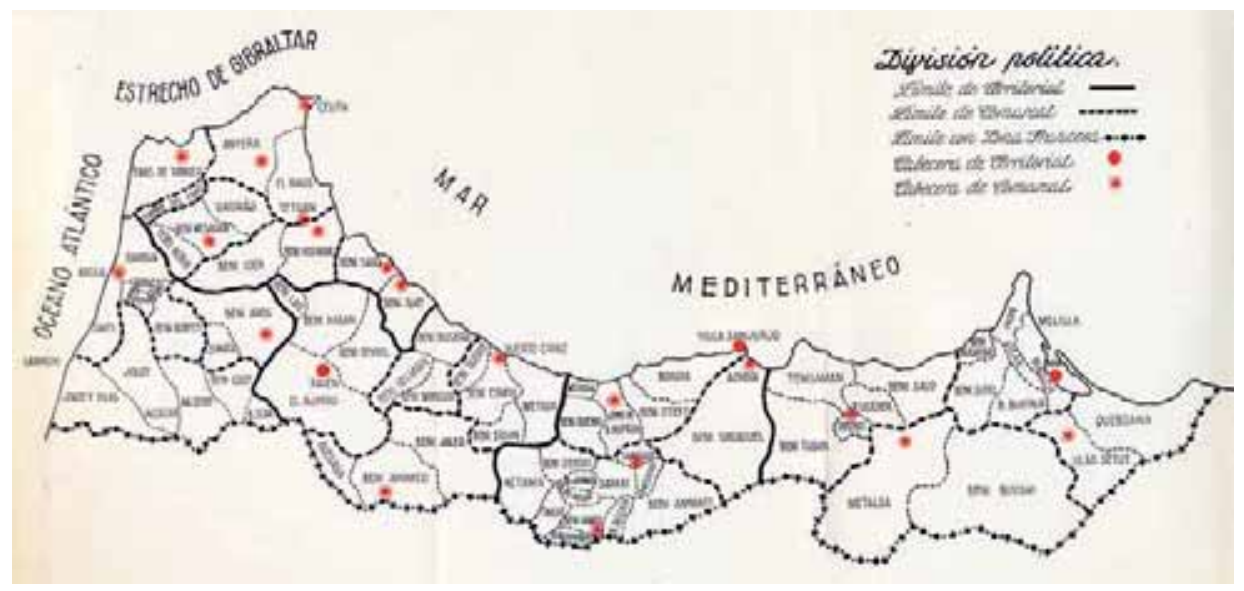

Fig. 1. Organización territorial del Protectorado a partir de 1927.

Pues no hay que olvidar que la función del Protectorado era, como reflejaba el artículo primero del Tratado de Madrid, "velar por la tranquilidad de la zona y prestar su asistencia al Gobierno marroquí para la introducción de todas las reformas administrativas, económicas, financieras, judiciales y militares que necesita”.

El Alto Comisario ostentaba la representación de España y de él dependían, inicialmente, tres Delegaciones: la de Asuntos Indígenas, la de Fomento y la de Asuntos Financieros, Tributarios y Económicos. En 1941 se crearon dos Delegaciones nuevas: la de Educación y Cultura y la de Economía, Industria y Comercio.

La Delegación de más alto rango fue la de Asuntos Indígenas que tuvo encomendado los Servicios de Sanidad e Higiene y de la que dependían los Interventores, que eran los auténticos y directos agentes responsables de la organización administrativa del Protectorado. 
La función de los Interventores consistía básicamente en la "fiscalización del uso que de su autoridad hacían las jerarquías indígenas”, aunque paralelamente se les adjudicó una amplia serie de atribuciones. Existían Interventores Territoriales, Comarcales y Locales, ya que cada región estaba compuesta por cábilas y cada una de ellas precisaba su propio interventor.

\section{Antecedentes de la acción sanitaria de Marruecos}

\section{La medicina mágico-religiosa, el curanderismo}

Entre los muchos problemas con que España se enfrentó al iniciar el régimen de Protectorado en Marruecos, figuraba el sanitario como uno de los más vivos y perentorios. También ha sido de los que mayores dificultades han ofrecido por parte del bereber, atado a sus prácticas por prejuicios religiosos y por tradición.

En Marruecos no existía con anterioridad ninguna organización que velara por la salud pública, salvo en Tánger, y las autoridades trataron de remediar esta deficiencia, creando en 1916 la Inspección de Sanidad, dentro de la Oficina de Asuntos Indígenas. Los "tobab" españoles (plural de "tebib”) (como eran conocidos los médicos) tuvieron que vencer la confianza que los marroquíes sentían hacia sus curanderos y a los remedios caseros, realizando grandes campañas de vacunación que contribuyeron al prestigio del país protector.

La mayoría de la población vivía en áreas rurales y, en ellas, la sanidad era casi inexistente y la asistencia médica corría a cargo de diversos tipos de sanadores, cuyas ideas sobre la salud y la enfermedad eran fundamentalmente de tipo empírico - creencial.

De un lado se encontraban los maalem jayam -Maestro barbero/sangrador- [2] y las kabblatz -comadronas-. Los primeros realizaban sangrías, cauterizaciones, extracciones dentales, reducción de fracturas, tratamiento de traumatismos leves, etc., y además disponían de un amplio arsenal de hierbas medicinales que prescribían de forma empírica [3]. Solían aprender al lado de un maestro experimentado. Se desplazaban de zoco en zoco y también acudían a las casas cuando se le llamaba. Las segundas, las kabblatz, 
acudían a las casas para los partos, ya que el rifeño no concebía "que dicho servicio fuera prestado por hombres".

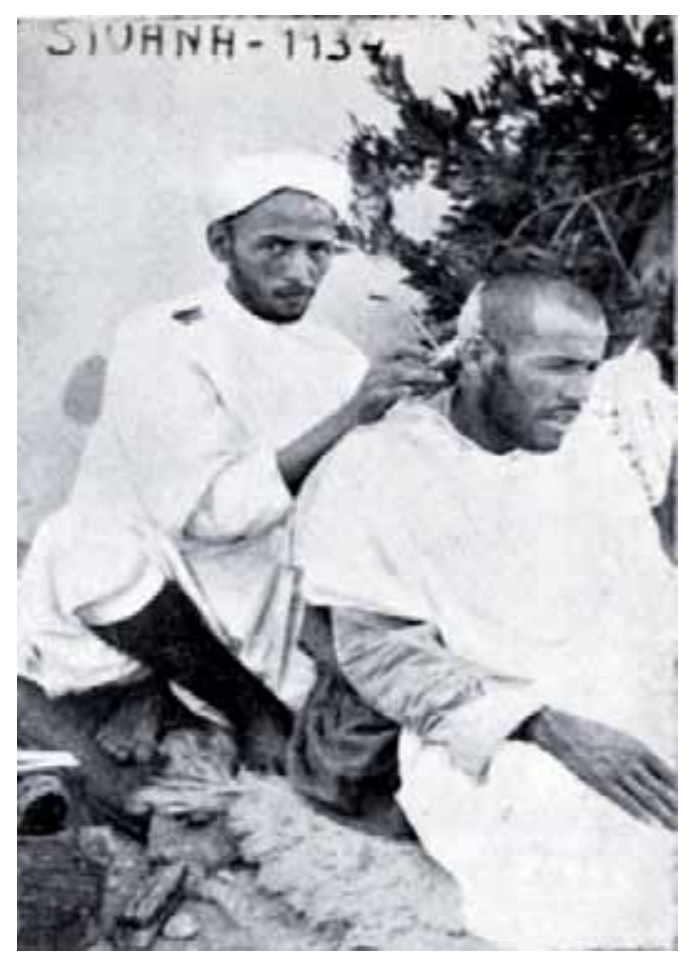

Fig.2. Maestro barbero/sangrador.

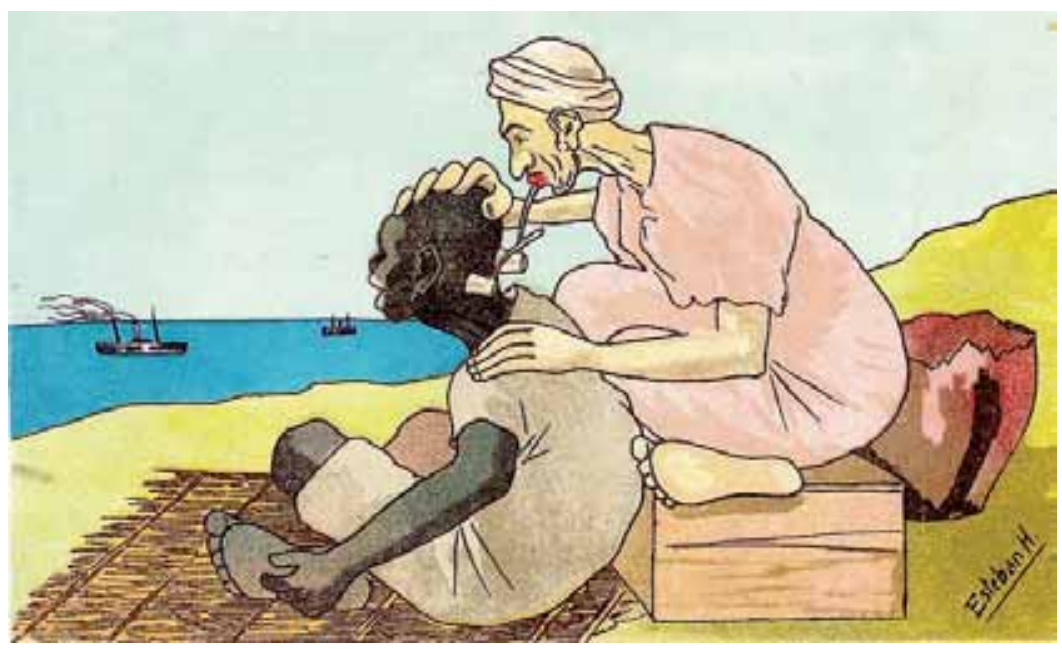

Fig. 3. Caricatura de un sangrador. Esteban $H$. 
De otro lado, se encontraban los chorfa, morabos o santones y los fokkah o alfaquíes. Los primeros tenían una función principalmente religiosa, ya que se encargaban del culto de algún santo en cualquiera de los morabitos (santuarios) distribuidos por el país. El cherif (singular de chorfa) poseía baraka, poder curativo atribuido a las personas de conducta ejemplar o a los descendientes del profeta Mohammed, con el que curaba enfermedades mediante la imposición de las manos. También se hacían ofrendas al santo o rituales para conseguir la curación de las enfermedades.

Por su parte, el fakih (singular de fokkah) solía ser un funcionario de la justicia islámica o un maestro, que elaboraba amuletos con signos cabalísticos o versículos del Corán (yeduil) [4] que los enfermos se colgaban al cuello, colocaban directamente sobre las heridas o zonas afectadas o bien ingerían. La distinción entre empíricos y religiosos no era tajante y en ambos casos se mezclaban procedimientos empíricos con creencias en espíritus, siempre bajo el manto de las prescripciones religiosas musulmanas.

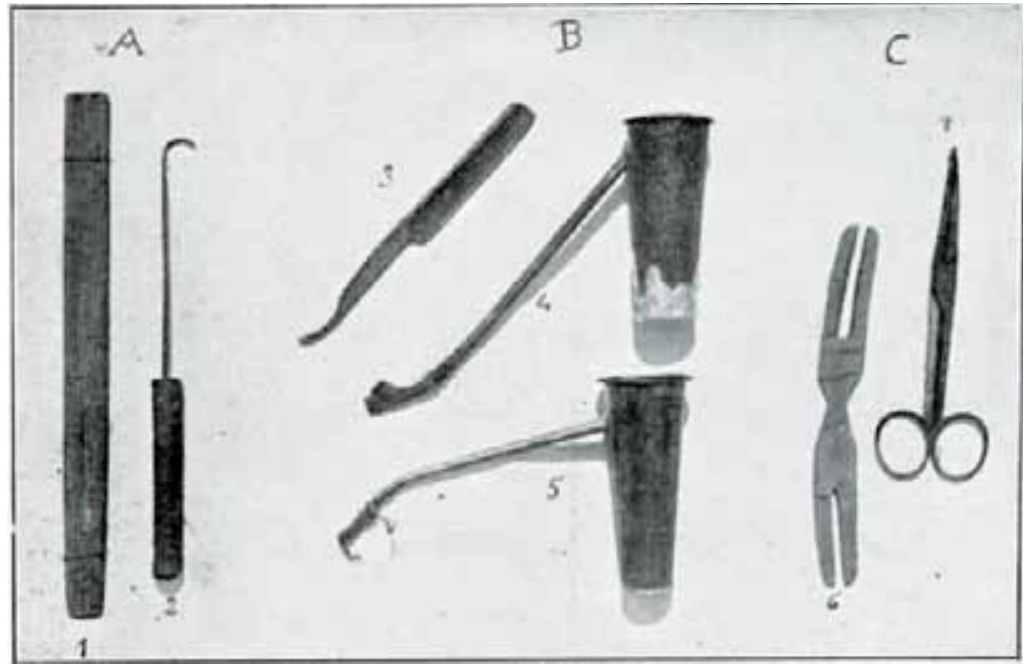

Fig.4. Instrumentos utilizados para a) extirpación de la úvula, b) sangría y c) circuncisión.

El Dr. José Crende, autor del trabajo titulado: "Confidencias de un Médico Agareno: Cómo practican la medicina los Moros en el S. XX” publicado en 1923, hace referencia de la existencia de médicos marroquíes, hom- 
bres eruditos, que de una manera autóctona se habían dedicado al estudio de los tratados de Avicena y Averroes.

Uno de ellos, también referenciado en el trabajo del Dr. Luis Herrero Muñoz, es el Cherif Sidi Mohamed Ben-Hosmi el Bakali [5], quién a parte de una medicina práctica adquirida por el uso, en la que existían unos tratamientos más o menos lógicos, era una medicina filosófica la que constituía el acervo de este Médico tetuaní, cuyo consultorio lo tenía en la Plaza de España y que se preciaba de poseer un Kanon de Avicena, el “Cordobés”, traído de España y llegado a sus manos por legado de padres a hijos.
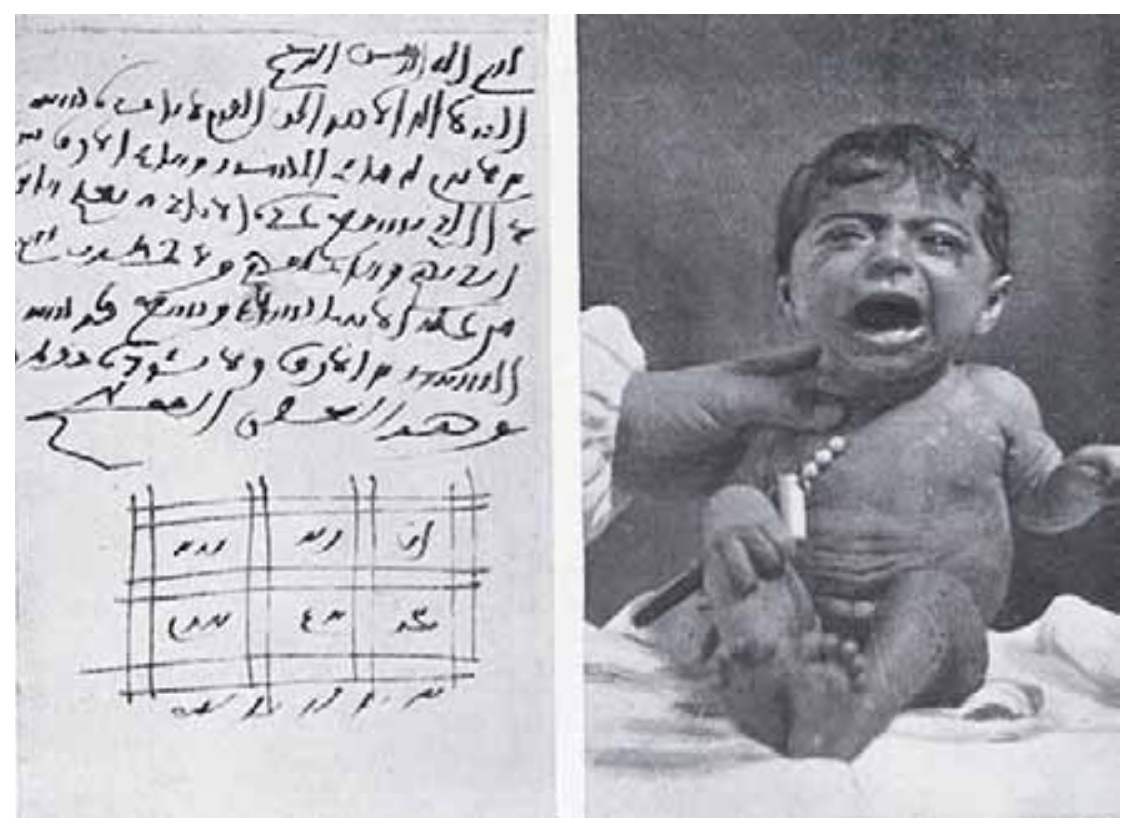

Figura 5. Yeduil (versículo del Corán) y amuleto.

Enfermedades más frecuentes

EL Dr. Herrero Muñoz [6], en su trabajo de Tesis Doctoral del año 1959, dice textualmente, al hablar de las enfermedades y patología general de la zona: "Empecemos por decir que en términos generales no podemos hablar de una patología "sui géneris”, y aquí podemos decir lo que decía Gaud del médico francés, que el médico español que viene a Marruecos, se en- 
cuentra con una medicina de la edad media, viruela, peste, paludismo, etc., pero enfermedades distintas a las metropolitanas no". Posteriormente hace una descripción de la patología más frecuente encontrada en su amplia y dilatada experiencia profesional en la zona de Tetuán.

Casi 20 años antes, el capitán médico Ignacio Iribarren Cuartero, en su trabajo, también deTesis Doctoral, titulado "Trabajos de un Médico Militar en el Rif, en la cábila de Beni-Said dice: "La patología de la cábila tiene poca diferencia con la patología europea en cuanto a clase de enfermedades". Y añade: "Por su situación geográfica y por su clima, no se presentan en ella las enfermedades llamada tropicales". Igualmente hace una descripción de las patologías más frecuentes en esa cábila [7, 8, 9, 10 y 11].

También es digno de destacar la publicación, en 1913, del trabajo titulado "Primera Memoria anual. Labor realizada y contribución al estudio de la Patología del Rif. Estadística”, del autor el Dr. José Valdés Lambea [12].

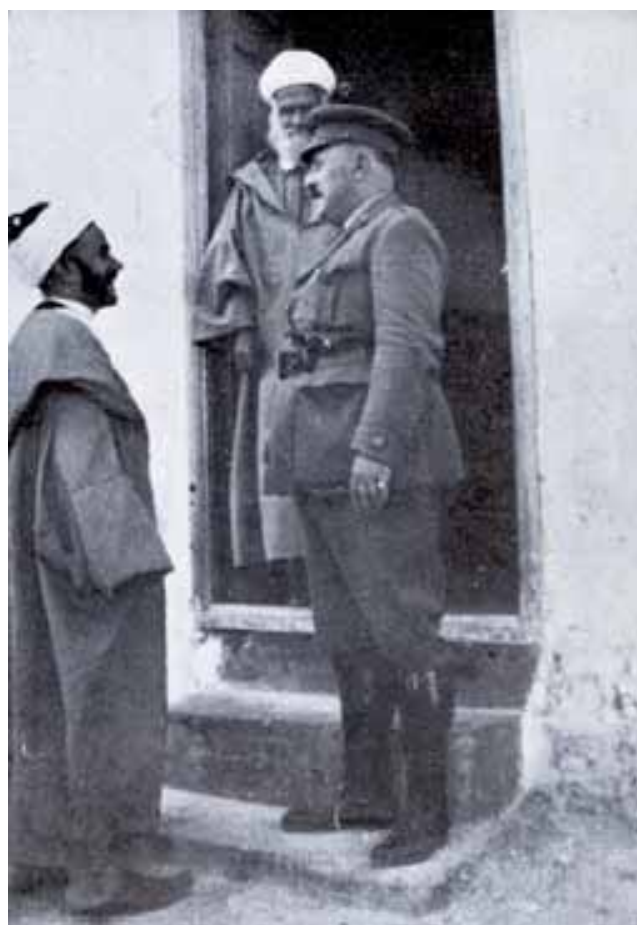

Fig.6. El Cherif Sidi Mohamed Ben-Hosmi el Bakali y el Dr. José Crende en Tetuán.

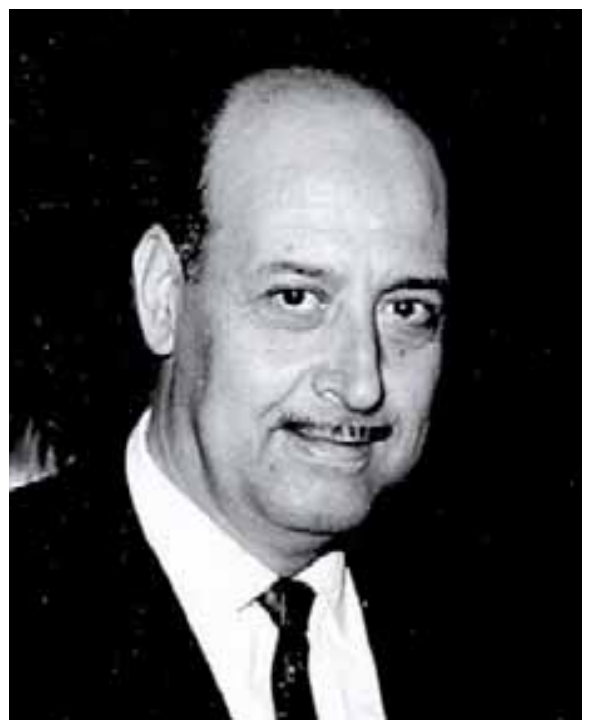

Fig. 7. Dr. Luis Herrero Muñoz. 


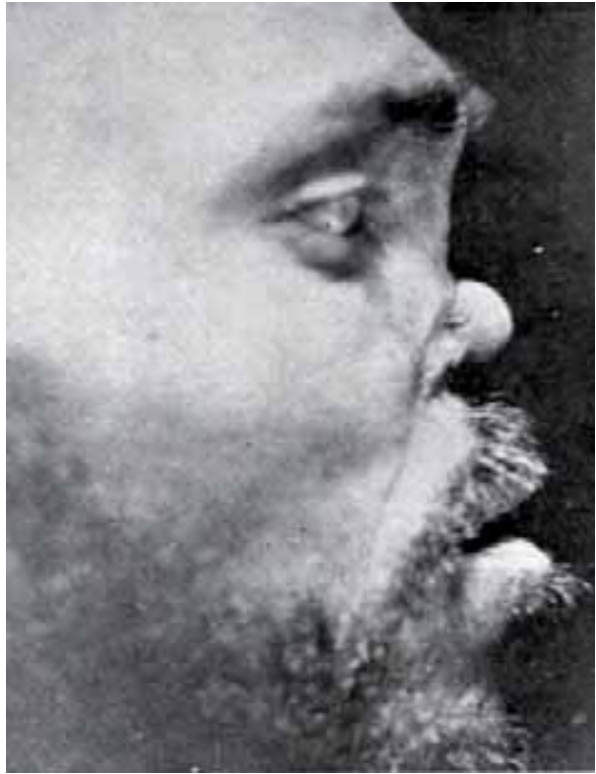

Fig. 8. Enfermedades más frecuentes; sifilis ósea destructiva: nariz en "pie de marmita".

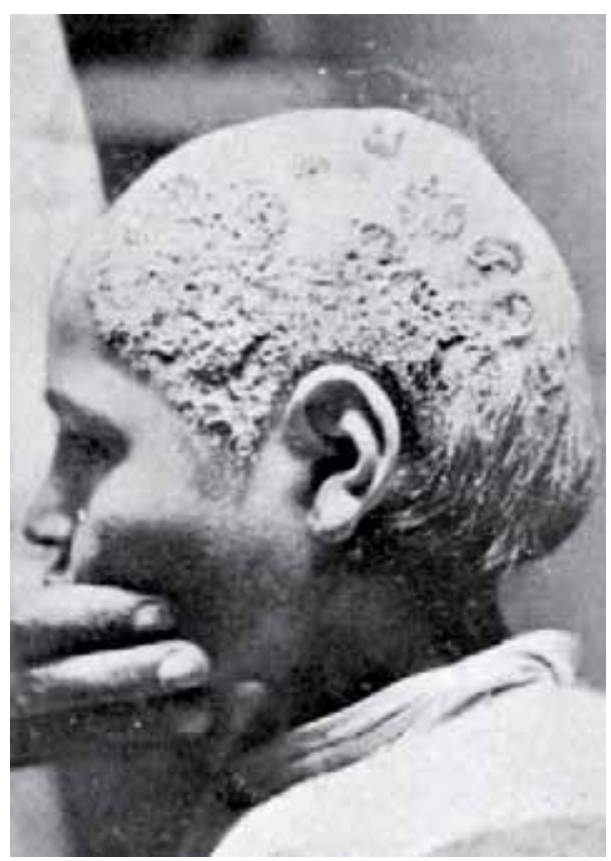

Fig. 10. Enfermedades más frecuentes: Tiña favosa del cuero cabelludo.

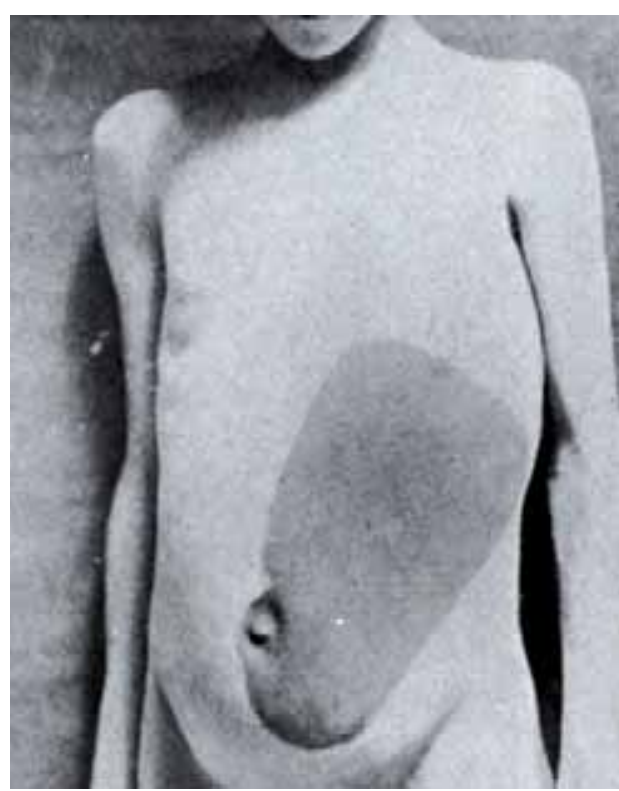

Fig.9. Enfermedades más frecuentes: gran esplenomegalia palúdica.

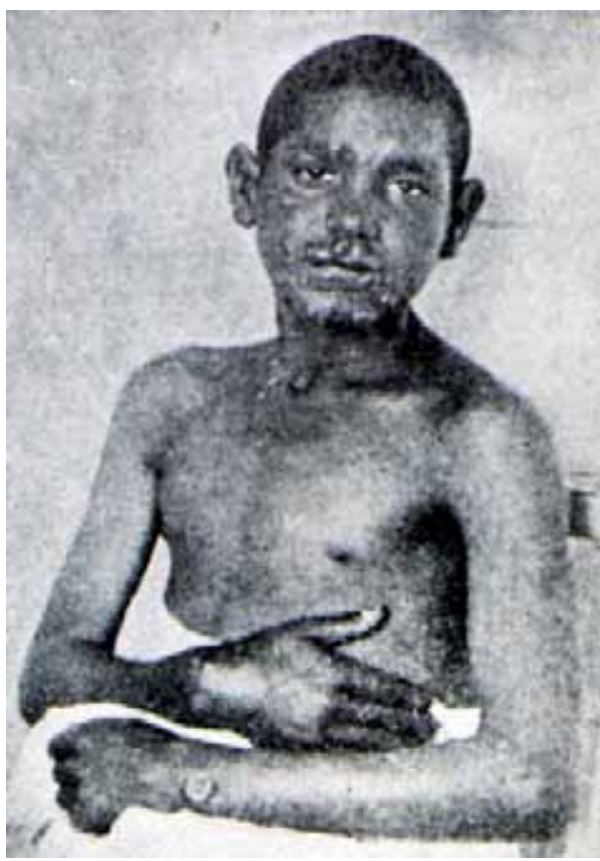

Fig. 11. Enfermedades más frecuentes: enfermo leproso. Lesiones en cara y manos. 
El Dr. Valdés fue el primer responsable del Dispensario Indígena de Nador, dependiente de la entonces Capitanía General de Melilla. En esa memoria hace una descripción de las distintas enfermedades que fueron tratadas, en ese Dispensario, a lo largo de 1913.

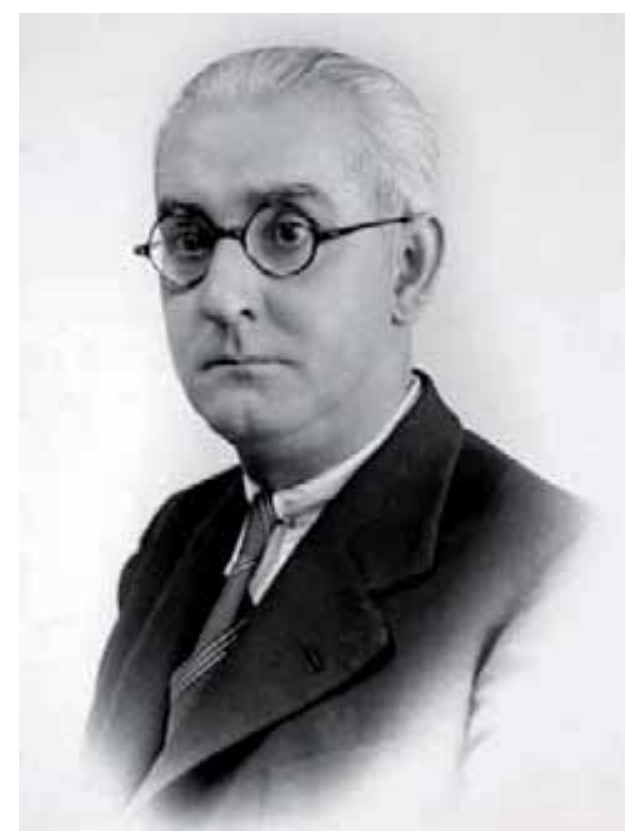

Fig. 12. Dr. JoséValdés Lambea.

En prácticamente la totalidad de los documentos consultados, se refleja que la sífilis, el paludismo y la viruela eran los tres grandes azotes de los campos magrebíes. Por ello, vacunando, inyectando neosalvarsán y repartiendo quinina comenzó la labor sanitaria que mejoró paulatinamente el estado de los rifeños.

\section{La sanidad antes del Protectorado}

Antes del inicio del Protectorado, España ya fue precursora en la implantación de una Sanidad moderna. En 1687 se fundó, en Meknès, el primer hospital moderno de Marruecos, con capacidad de veinte camas, y el mismo año se instala la primera farmacia aneja al mismo. Destruidos ambos edificios por el terremoto de 1775, fueron nuevamente levantados en 1779 . 
Uno de los primeros hospitales modernísimos erigidos en Tánger [13] fue español, inaugurado en 1888, con capacidad para cuarenta camas. Asimismo, las primeras farmacias modernas de Marruecos fueron abiertas en Tánger por farmacéuticos españoles.

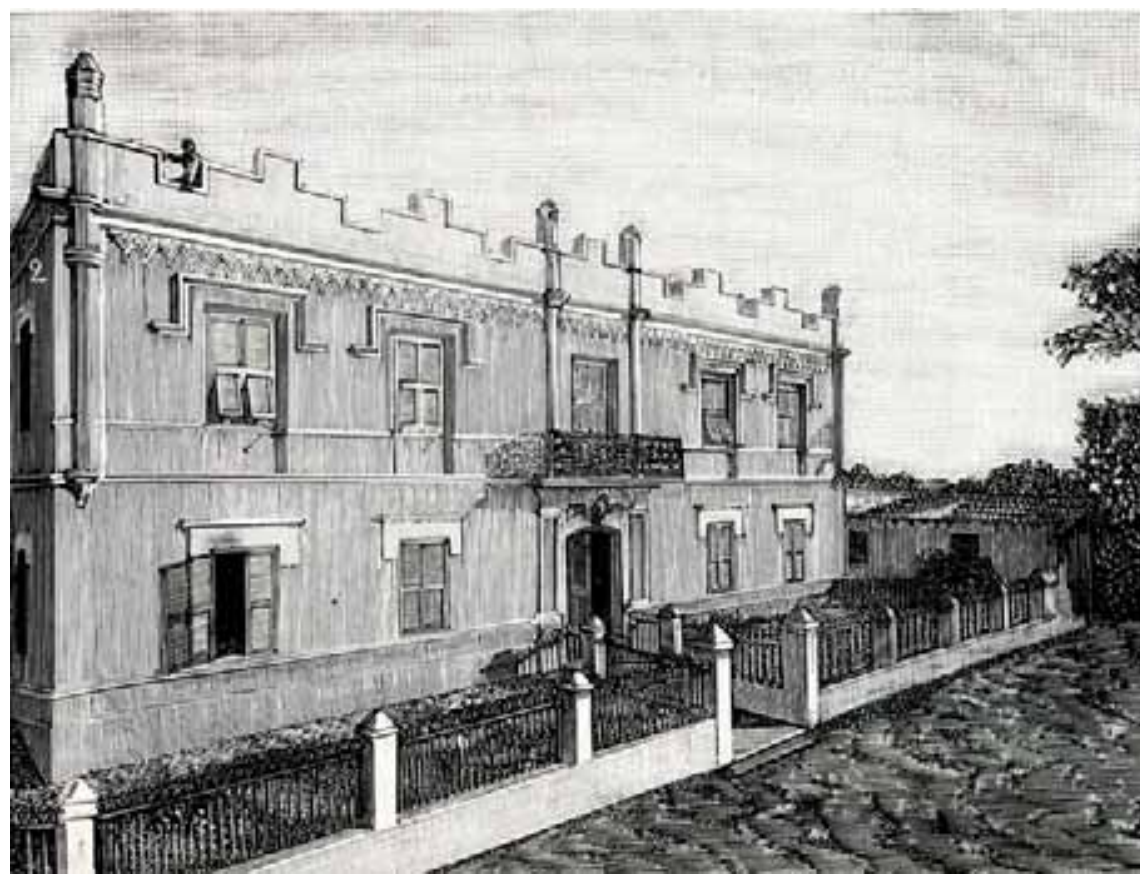

Fig. 13. Antiguo Hospital Español de Tánger.

Más aún, ya en 1886 comenzó su andadura en Tánger la primera Escuela de Medicina de Marruecos. Era española y la dirigía el médico de Sanidad Militar Dr. Felipe Ovilo Canales [14]. En ella adquirían conocimientos médicos elementales y prácticos los misioneros franciscanos españoles y jóvenes musulmanes con aptitud para ello.

Las primeras tentativas de moderna organización sanitaria del imperio marroquí nacieron de la necesidad, por una parte, de los europeos establecidos en las ciudades de la costa y, por otra, del interés del propio Sultán y el Majzén en poner en marcha instituciones sanitarias modernas, sobre las que conservaron una cierta capacidad de decisión. 
Así nació el Consejo Sanitario de Tánger, o Consejo Sanitario Marítimo de Tánger, creado por el Sultán en 1840, con el fin de responsabilizarse del mantenimiento de la salud pública en el litoral Cherifiano. A partir de 1847 se establecieron delegaciones en Larache, Rabat, Casablanca, Mazagan, Safi y Mogador y montó servicios en los principales puertos marroquíes. En 1865 se estableció, en la isla de Mogador, un lugar de cuarentena para los peregrinos que volvían de la Meca y poder, así, aislarlos en caso de sospecha de cólera.

Pero, salvo estas meritorias tentativas de consolidación definitiva de una gran obra sanitaria y social en Marruecos, emanadas casi principalmente de la iniciativa y del esfuerzo privado español, todo en Marruecos, en materia sanitaria, estaba por hacer y había que acometer con toda urgencia.

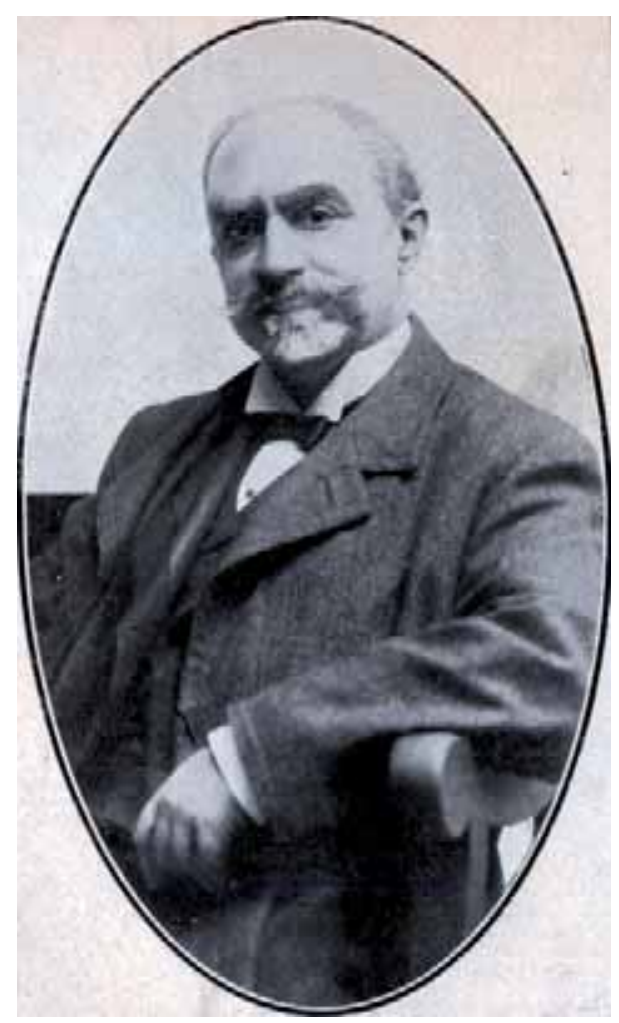

Fig. 14. Dr. F. Ovilo Canales. 


\section{La protección de España en Marruecos en materia socio-sanitaria}

\section{Organización Sanitaria}

El protectorado se caracterizó por la fuerte militarización a todos los niveles, resultado tanto de la debilidad de la acción civil española, como de la resistencia armada de los rifeños y de la imitación del modelo colonial francés en el norte de África.

La Alta Comisaría contempló la labor sanitaria más como un instrumento de penetración y atracción que como un medio para mejorar las condiciones de vida de la población. Por ello, la sanidad y la medicina, marcharon al paso del avance militar español y sirvieron a propósitos de "penetración y pacificación”, más que de civilización. Por estos motivos, su implantación en el campo corrió a cargo de las Intervenciones.

La institución o espacio más representativo y más específico de la actuación médico-sanitaria española en Marruecos fue el Dispensario Indígena, también llamado Consultorio, al que me referiré más tarde.

Decía el militar africanista Tomás García Figueras (que llegó a ser Secretario de la Alta Comisaría) en su obra Acción de España en Marruecos, en 1926, y con relación a la acción sanitaria: "enlazan sólidamente al indígena con el protector por vínculos morales, crean en él la gratitud, lo habitúan al trato con hombres que ejercen influencia beneficiosa sobre sus autoridades legítimas y ponen de relieve de modo que no deje lugar a dudas el carácter eminentemente pacifista y desinteresado de la obra que España realiza en Marruecos por mandatos internacionales".

Llegada la pacificación total, la nación protectora orientó los servicios médicos y sanitarios públicos hacia una organización estable y progresivamente más completa. En 1929 se creó el Órgano Central Director de la Sanidad e Higiene públicas en la zona, y ese mismo año se dictan las normas generales para todas las cuestiones referentes a la Sanidad.

Diez años más tarde, en 1939, se puso en práctica la Organización de la Sanidad Oficial del Protectorado, como Servicio exclusivamente estatal, abarcando todos los servicios médico-sanitarios: los de orden local, regional y nacional. 
Esta organización, de importancia extraordinaria, logró un señalado éxito y persistió y fue perfeccionándose al correr de los años, hasta el fin del Protectorado, en abril de 1956.

Su cabeza era la Dirección de Sanidad e Higiene Públicas, o Inspección de Sanidad, como se llamó en un principio, órgano de dirección técnica e inspección médico-sanitaria, que dependía directamente de la Delegación de Asuntos Indígenas de la Alta Comisaría.

Su estructura interior comprendía diez secciones [15], pero sólo me referiré a dos de ellas, la $4^{\text {a y }} 5^{\text {a }}$; es decir, a "Los Servicios" y "Las Luchas y Campañas Sanitarias”, respectivamente.

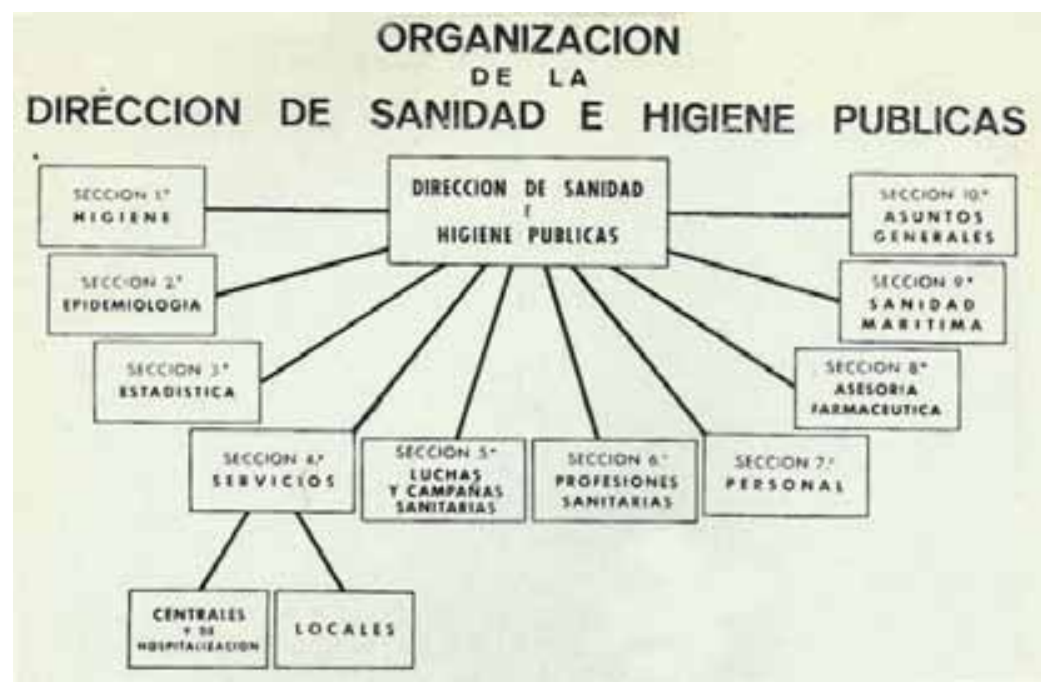

Fig. 15. Organización sanitaria.

Sección 4 ${ }^{a}$. Los Servicios de la Dirección General

Los Servicios de la Dirección General de Sanidad eran los que realmente realizaban la tarea médica cerca de la población. Constaban de Servicios Centrales y de Hospitalización y Servicios Locales.

I. Los Servicios Centrales comprendían los de alcance a todo el Protectorado y estaban constituidos por: 
1. El Instituto de Higiene de Tetuán, establecimiento dotado para el estudio de los problemas higiénicos, epidemiológicos y sanitarios en general.

2. El Servicio Farmacéutico, que comprendía los laboratorios de medicamentos y material sanitario y las Farmacias. De los primeros había uno en Tetuán que se denominaba Central y otro en Villa Nador, filial del primero [16].

II. Los Servicios de Hospitalización comprendían:

1. Los Hospitales Civiles, que eran cinco: en Tetuán, Larache, Villa Nador, Alcazarquivir y Villa Sanjurjo, con capacidad total de 710 camas.

2. El Sanatorio antituberculoso de Ben Karrich, a $10 \mathrm{Km}$ de Tetuán.

3. El Sanatorio enfermería marítima de Arcila, pequeño establecimiento especializado en el tratamiento de las afecciones óseas y ganglionares tuberculosas de la infancia.

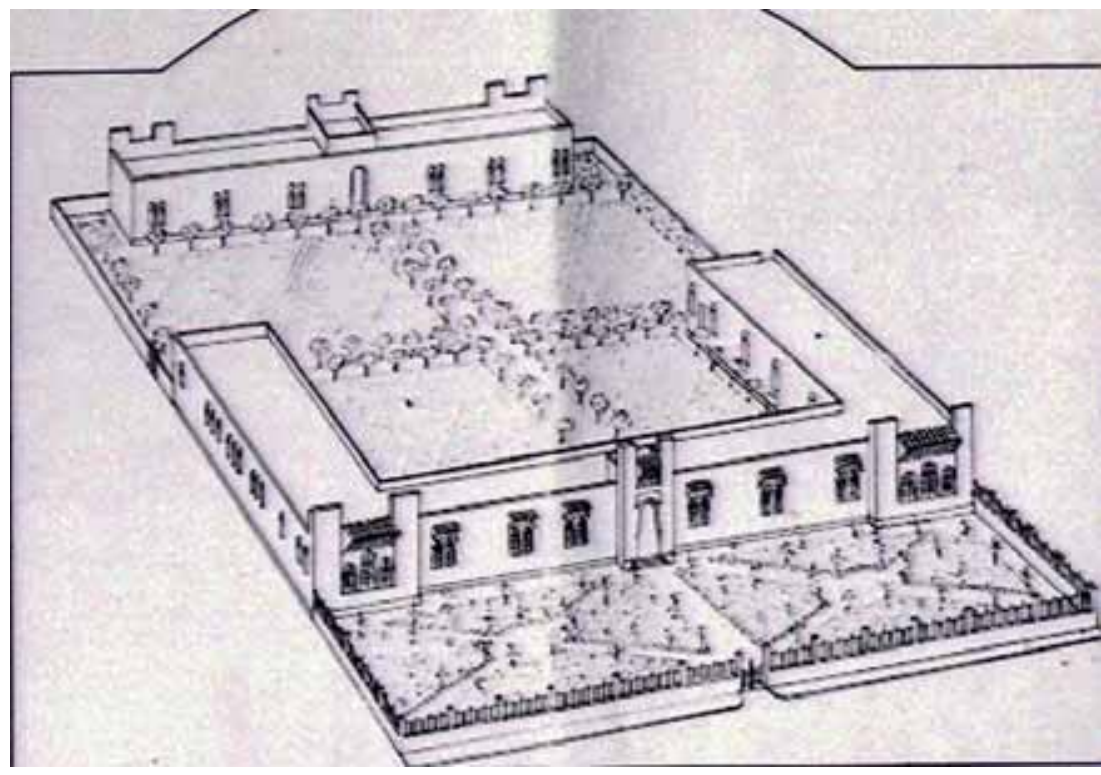

Fig. 16. Hospital Civil de Nador. 
Además, anejo a los hospitales civiles funcionaban pabellones y servicios de maternidad, orientados a mejorar las condiciones sociales de la natalidad.Y anejo al hospital Civil de Tetuán se construyó un pabellón para la clínica de pediatría y servicio de puericultura y centro de alimentación infantil.

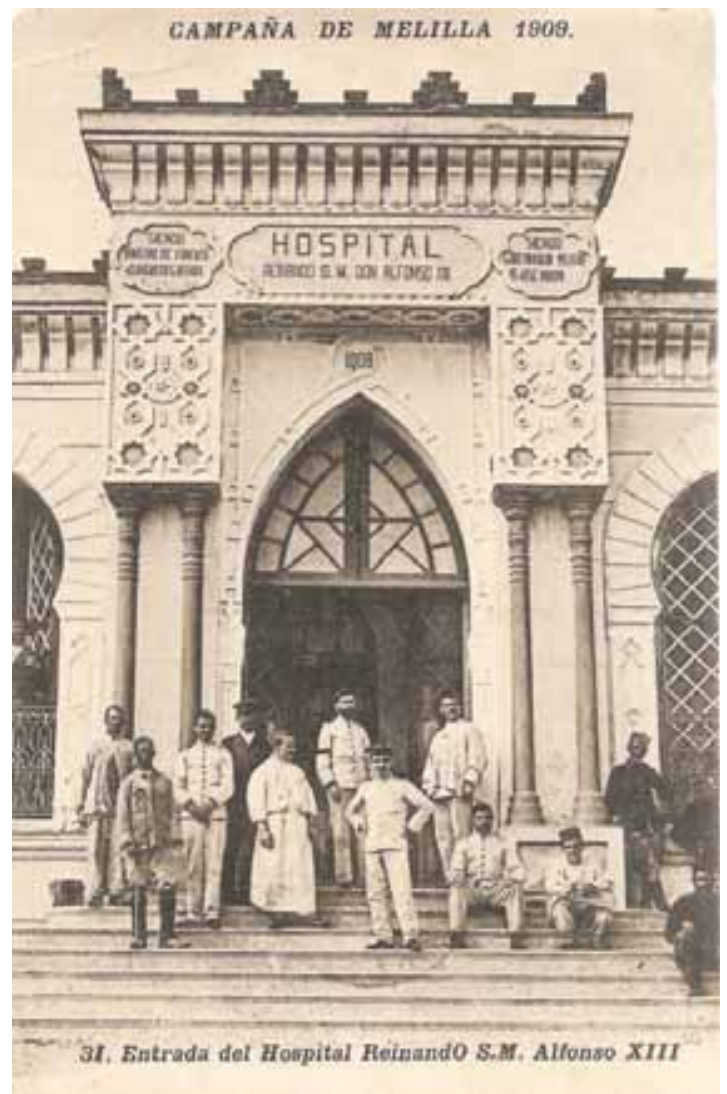

Fig. 17. Hospital Indígena de Melilla.

\section{Hospital Indígena de Melilla}

En un intento para congraciarse con los marroquíes fronterizos, el Ministerio de Estado autorizó en 1907 la creación y construcción, en Melilla, de un hospital o enfermería dedicada con exclusividad a los marroquíes: el llamado Hospital para Indígenas [17]. Se eligió su ubicación en las cercanías del barrio del Polígono, por ser en aquella época donde vivía la mayoría de la población musulmana asentada en la ciudad. 
Era de ornamentación arábiga e incluso se pensó con la posibilidad de construir una mezquita adjunta más adelante. El proyecto era del ingeniero de la Junta de Obras del Puerto Manuel Becerra, entonces en Melilla, quien años más tarde llegaría a ministro de la República.

No hubo tiempo de poner en práctica la idea del nuevo hospital. Aunque se construyó y terminó en 1909, precisamente los acontecimientos de ese año se echaron encima y ante la demanda de hospitales hubo que habilitar la enfermería indígena para infecciosos. En 1926, el general Castro Girona, con el objeto de economizar gastos, ordenó el cierre de la enfermería, pasando los enfermos al hospital Alfonso XIII y al Docker. En 1933 pasa a ser Escuela de Artes y Oficios.

\section{Los Servicios Locales}

Los Servicios Locales radicaban en las ciudades y en el campo, cuidaban de la asistencia médica y sanitaria de la población, con carácter ambulatorio y a domicilio, y de la práctica de las medidas higiénicas y sanitarias pertinentes.

En las ciudades comprendían las Inspecciones Locales de Sanidad, afecta a las Intervenciones respectivas, y los Centros y Consultorios médicos Urbanos.

Además, para atender la especial idiosincrasia del pueblo musulmán, se crearon en Tetuán, Larache y Alcazalquivir, servicios exclusivos para el sexo femenino, que se denominaron "Consultorios de mujeres y niños musulmanes", atendidos por personal facultativo y auxiliar también femenino exclusivamente.

En los núcleos de población de alguna importancia se crearon los llamados Centros Médicos y de Higiene Rural, los cuales, además del trabajo médico y sanitario propio de un Centro Médico, disponían de enfermería mixta aneja.

El campo marroquí se dividía, a efectos médicos y sanitarios, en los llamados Círculos Médicos, que eran las Inspecciones locales de Sanidad en el campo; estaban afectos a las Intervenciones de las cábilas, y si bien, generalmente cada Círculo Médico correspondía a una jurisdicción interventora, 
había algunas de éstas que por su gran extensión y población poseían más de un Círculo Médico. El número de Círculos Médicos se elevó a 41.

A la cabecera de cada Círculo Médico había un Consultorio Médico Rural, casi siempre emplazado en las proximidades de los zocos o mercados importantes. [18]

Para la asistencia médica de las poblaciones muy alejadas geográficamente de los Consultorios Médicos Rurales existían los llamados Puestos Sanitarios, atendidos, a permanencia, por un practicante español y sanitarios marroquíes; estos puestos eran visitados semanalmente por el médico del Círculo, con objeto de indicar la labor a seguir y vigilar la que estaba en curso. El número de puestos sanitarios se elevó a 26.

En los zocos de interés, en cuyas proximidades no habían consultorios médicos o puestos sanitarios, se crearon y funcionaron los llamados Lugares de Consulta Semanal, en cuyos locales, el médico del Círculo visitaba semanalmente el día de mercado, en función principalmente sanitaria, de tratamiento de las principales endemias y de vigilancia y de propaganda médica en general.

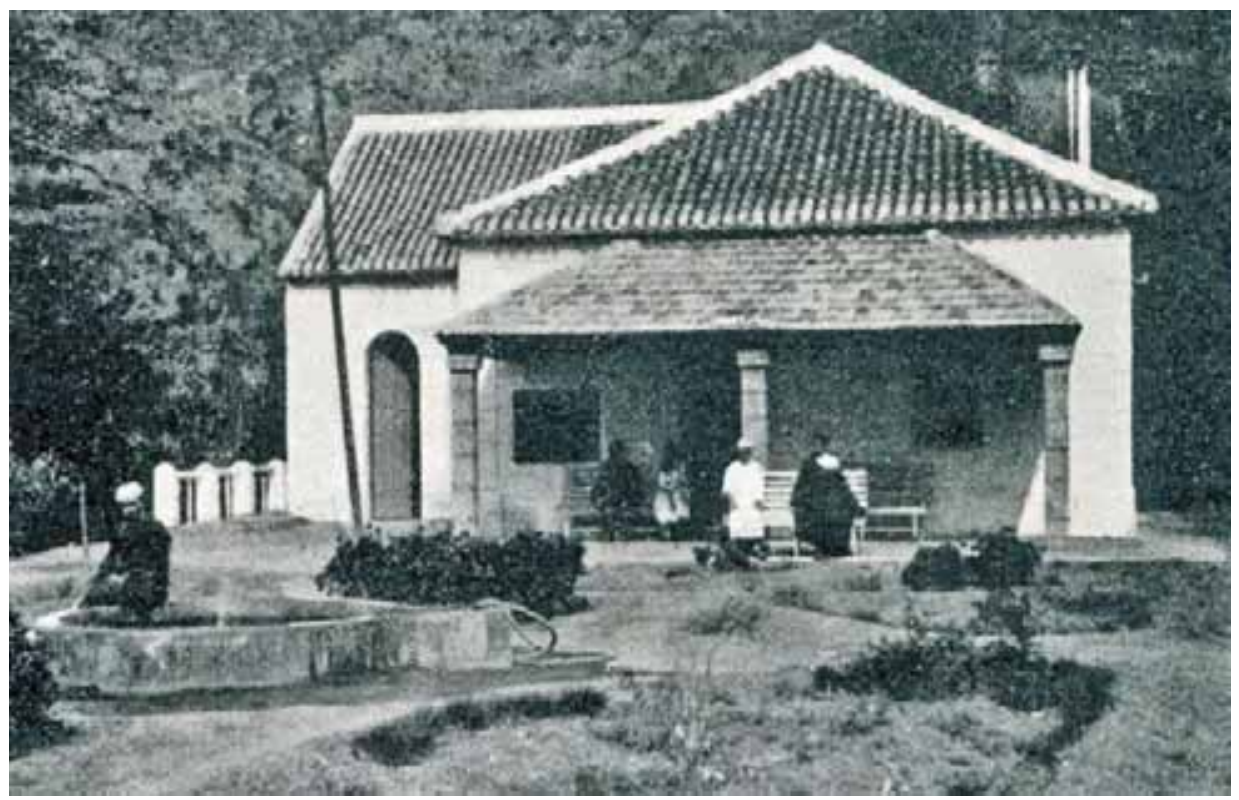

Fig. 18. Círculo médico de Tabarrant. 
No estará de más decir que todos los servicios médicos prestados en los Centros de Hospitalización y en los Consultorios Médicos de toda clase, fueron siempre completamente gratuitos y también se daba gratuitamente la medicación para el tratamiento de las enfermedades.

\section{Los Dispensarios}

Como decía, la institución o espacio más representativo y específico de la actuación médico-sanitaria española en Marruecos fue el "Dispensario", también llamado Consultorio [19].

Una red de estos dispensarios se fue implantando conforme se ocupaba militarmente la zona asignada a España. El primero se crea en 1912, en Beni Chicar, que lo dirige el comandante médico Merás. Posteriormente se van abriendo nuevos consultorios. Ya en el presupuesto para el ejercicio de 1915 se consignan cantidades para 9 en la Zona de Melilla, 7 en la Zona de Larache y 2 en la Zona de Tetuán.

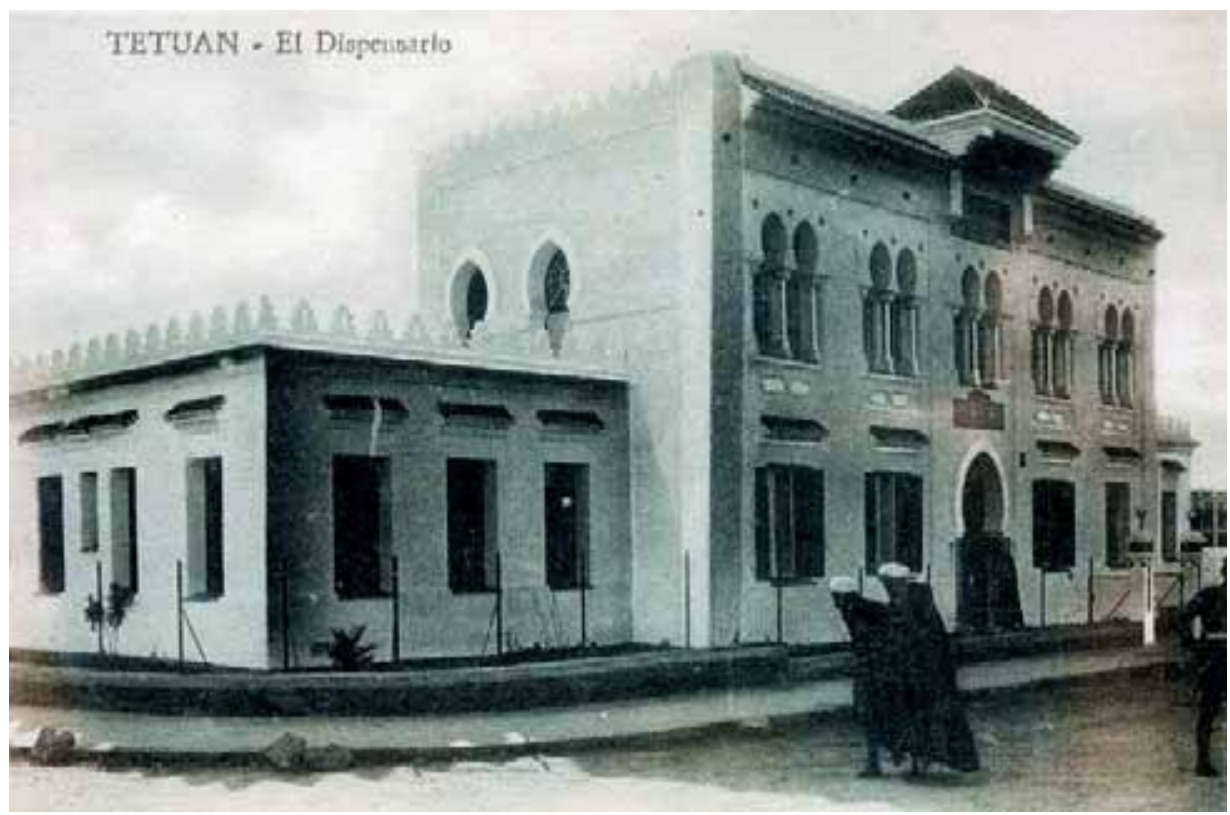

Fig. 19. Dispensario de Tetuán. 
En el Consultorio Médico Rural residía el médico y éste desarrollaba en él la principal labor.

Tras una primera fase de expansión y consolidación que duró hasta 1921, dicha red quedó reducida al mínimo como consecuencia del desastre de Annual y la posterior ofensiva rifeña que se prolongó hasta 1925. A partir de este momento y siguiendo el avance militar hispano-francés, que comenzó con el desembarco de Alhucemas, se estableció la red de dispensarios que habría de mantenerse esencialmente hasta el final del protectorado en 1956.

Los dispensarios se localizaban en las proximidades de los zoco, con objeto de que su acción fuera lo más próxima posible a la población y mayor su efecto. Además, estaban físicamente adheridos a las oficinas de intervención militar y a las escuelas, las otras instituciones que constituían la "avanzada” de la acción española, de forma que sus actividades se reforzaban mutuamente. En algunos casos se establecieron consultorios en las proximidades de la Zona francesa, para mostrar que la acción española no desmerecía de la desarrollada por Francia.

Esto era así, porque los dispensarios formaban parte de esa estrategia de "penetración" y "pacificación” que los españoles habían copiado del general francés Lyautey y dentro de ésta, la asistencia médica y las medidas sanitarias servían para compensar a la población por los daños de la guerra, para mostrarles las ventajas de la civilización europea y para facilitar por ambos medios la ocupación del territorio por parte del ejército, paso previo necesario para la implantación de la administración protectora.

En la obra El Dispensario Indígena de Nador, de J. Valdés, figuran varias citas que merecen ser tenidas en cuenta. Son las siguientes:

1."Si pretendemos aniquilar, derrochemos pólvora y sembremos enfermedades. Si pretendemos civilizar y hacer un nuevo pueblo, difundamos las ciencias y las artes. Enseñemos higiene y mejoraremos la raza”.

Juan Felipe De Lara San Juan. De Madrid a Uxda, 1913 
2."En cada puesto haré establecer una enfermería indígena....espero que una vez curadas sus enfermedades llevarán a sus aduares un sentimiento de gratitud hacia nosotros, el cual contribuirá pujantemente a fomentar las relaciones pacíficas".

General Hubert Lyautey

Puede decirse que la actuación médico-sanitaria española dirigida a la población rifeña, evolucionó desde la labor descoordinada de los médicos militares de las unidades del ejército, hasta la acción coordinada de los médicos emplazados en la red de dispensarios indígenas.

La actuación de los médicos en Marruecos constituyó un brillante y definitivo éxito para el pueblo marroquí y para España.

\section{Sección $5^{a}$. Luchas y Campañas Sanitarias}

Un factor fundamental en la tarea emprendida estaba representado por la labor de la sección $5^{a}$ de la Dirección de Sanidad, que regía las Luchas y Campañas Sanitarias.

Su desarrollo corría a cargo de los Inspectores Locales de Sanidad y de los Directores de los Círculos Médicos, con su personal de plantilla, y el que se le agregaba cuando las circunstancias lo aconsejaban.

Las Luchas Sanitarias significaban actuación permanente, y las Campañas, acción periódica o accidental.

En ocasiones la puesta en marcha de las Campañas Sanitarias era precedida de Propaganda divulgadora [20, 21, 22 y 23], en árabe y español, por medio de charlas radiodifundidas, artículos y entrefiletes en la prensa, carteles murales llamativos y folletos y hojillas manuales, en la que, de manera sencilla y gráfica, se pretendía enseñar, convencer y atraer. Igual propaganda se realizaba de manera periódica para las principales luchas: la antipalúdica, la antituberculosa, la de higiene infantil y la divulgadora general higiénica.

Resultados obtenidos y situación médica y sanitaria al entregar España su zona de Protectorado al nuevo Estado marroquí. 
Decía, en 1953, el prestigioso hispanista marroquí Mohammad Ibn Azzuz Haquim, que "pocos Servicios hay tan interesante desde el punto de vista de la atracción del marroquí hacia la civilización y el progreso, como el de la acción sanitaria del Protectorado, misión que es digna del mayor encomio y debe ser objeto de gratitud y admiración por parte de todos".

Mantenía el historiador que desde hacía tiempo, el marroquí estaba convencido de los grandes beneficios que el médico le reportaba y era por días cómo se veía incrementar el número de asistencias en los Consultorios médicos oficiales. Tal es la fe que el marroquí medio, e incluso el de las bajas capas sociales (donde la superstición causa verdaderos estragos), iba adquiriendo en el "tabib", que contra su costumbre inveterada de tener ocultas a sus mujeres, acudía con ellas al médico, y en casos graves reclamaba la asistencia de éste para partos y enfermedades propias de la mujer.

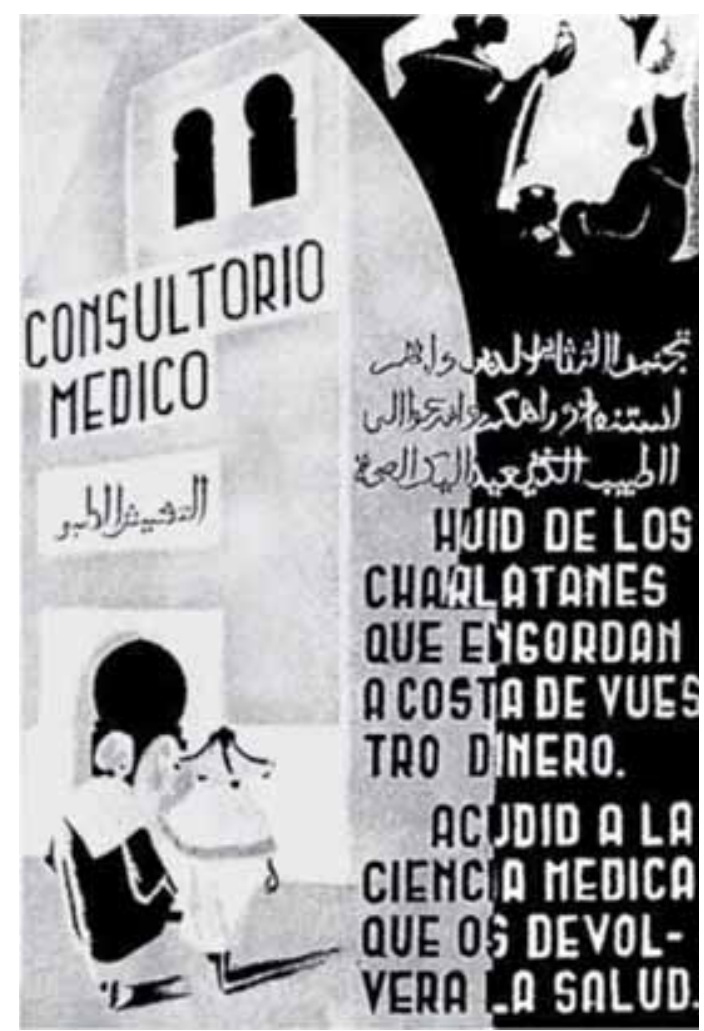

Fig.20. Cartel propaganda de Consultorio. 


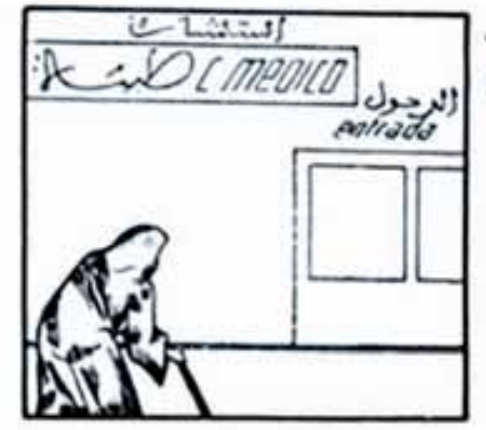

Si hav tenido puludiuno o le judeces aìn acude

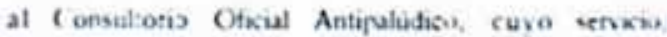
Rratuito, te curard y vigitard para que fecobecs a slud y no was un pelingro puta bis derus

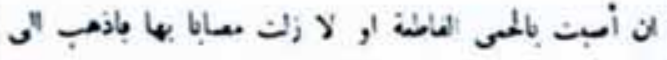

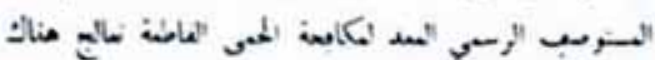

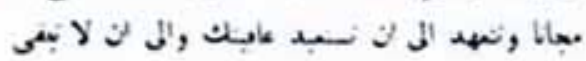

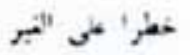

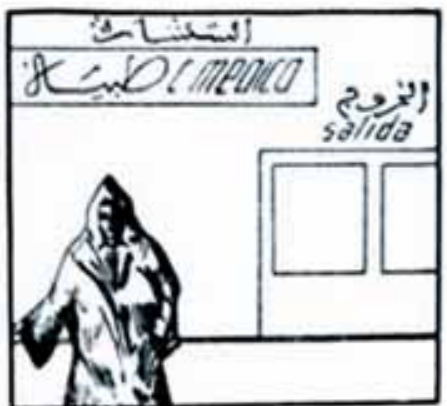

Fig.21. Cartel anunciador antipalúdico.

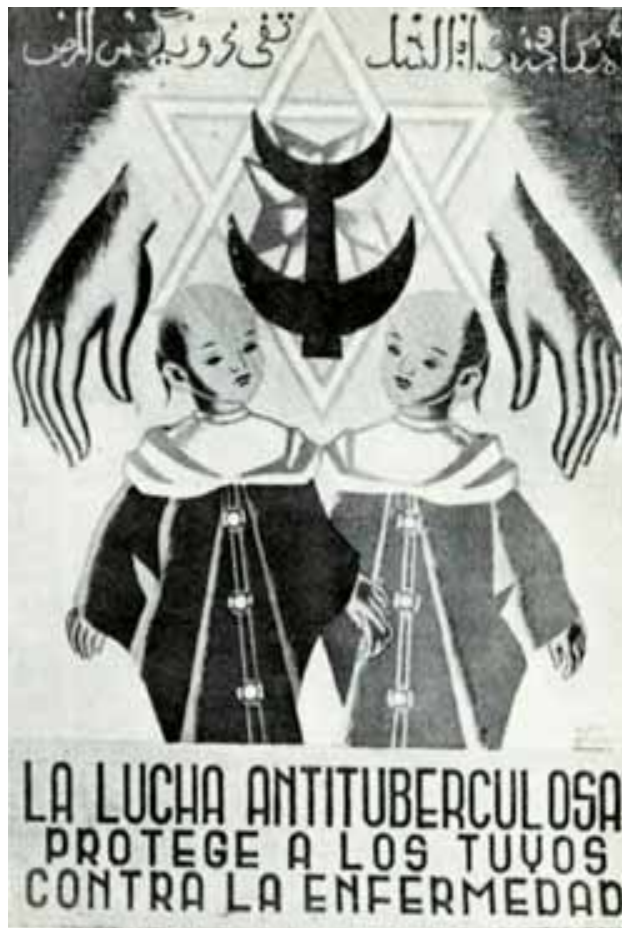

Fig.22. Cartel mural antituberculoso.

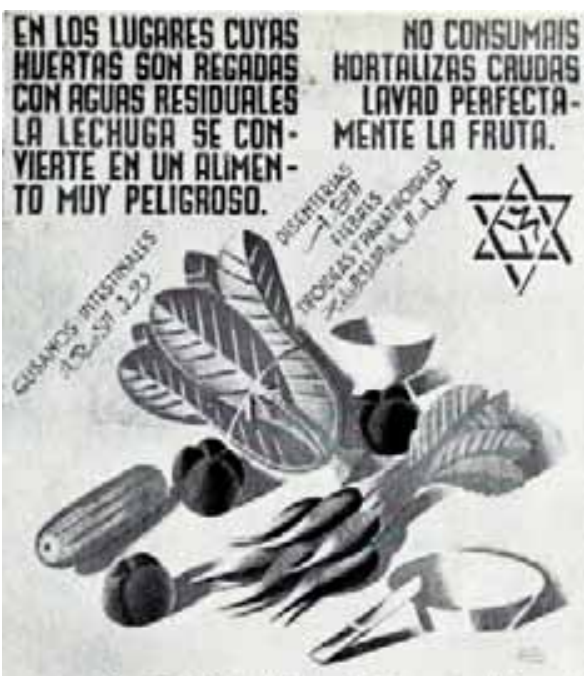

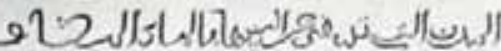

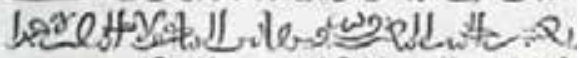

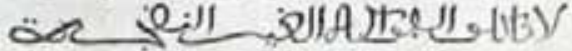

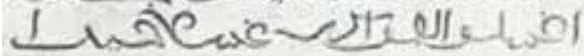

Fig.23. Cartel profilaxis fiebre tifi-paratíficas. 
Pero con ser importante la labor médica de asistencia, no lo fue en el fondo tanto como la labor sanitaria. Esta fue la principal misión que se cumplió más lenta y callada que la anterior.

La acción de España en Marruecos, como país protector, duró legalmente 44 años, desde 1912 a 1956. La labor sanitaria comenzó desde el primer momento, pero durante los primeros 15 años, hasta la paz de 1927, aquella se desarrolló de manera incompleta, debido a los avatares de la acción armada de pacificación de las comarcas insumisas a la autoridad del Sultán.

Finalmente, en los últimos 29 años, la acción sanitaria pudo llegar a todo el territorio marroquí confiado a España y se proveyó de los siguientes logros:

1. De una Legislación Sanitaria completa, por una parte moderna y por otra adaptada a las necesidades e idiosincrasias del país.

2. De personal facultativo médico, farmacéutico y químico y de personal auxiliar técnico y sanitario, español y marroquí, masculino y femenino, de todos los grados y especialidades.

3. De un gran número de edificios para servicios médicos y sanitarios, esparcidos por toda la geografía de nuestra Zona.

4. De instalaciones, material e instrumental científico-médico, clínico, quirúrgico y sanitario de toda clase.

5. De servicios médicos y sanitarios diversos, en ordenado funcionamiento:

a. Los de tipo investigador del Instituto de higiene.

b. Los de tipo asistencial ambulatorio y a domicilio de los Centros y Consultorios Médicos.

c. Los de hospitalización, para enfermos de toda clase de afecciones, de los hospitales y sanatorios.

d. Los de tipo sanitario de las Inspecciones Locales de Sanidad y Círculos Médicos. 
e. Los de protección a la madre y al niño con las Maternidades y Centros de Puericultura.

6. De luchas y Campañas Sanitarias que en unos pocos años de generosa labor consiguieron las siguientes grandes victorias, entre un sin fin de actuaciones:

a. La desaparición de las formas clínicas mutilante de la sífilis endémica.

b. La desaparición de las graves epidemias palúdicas y la reducción de la endemia palúdica a cifras cercanas a cero.

c. La desaparición de las grandes epidemias que atormentaban al país: viruela, tifus exantemático, disenterías y afecciones tifo-paratíficas, $\mathrm{y}$

d. La reducción de la elevadísima mortalidad infantil, fruto de la lucha contra las afecciones infecto-contagiosas y nutritivas de la primera y segunda infancia.

Además, mantenía el Dr. Solsona que "existe un significativo eslabón, que también acredita nuestra limpia conducta de tutela: La Formación de Personal Sanitario".

Desde un principio, o sea, desde la implantación del Protectorado, al lado del médico y del practicante españoles ha existido siempre un enfermero y una enfermera marroquíes, cuya labor se reducía casi exclusivamente a las de servir de intérpretes del facultativo o de auxiliar cerca de sus enfermos marroquíes de uno y otro sexo.

A medida que los habitantes de la Zona iban comprendiendo mejor cuán beneficiosa es la ciencia del médico, se hacía necesario que tales subalternos marroquíes fuesen de una formación un tanto elevada, e incluso que dejaran de ser simples subalternos para convertirse en verdaderos auxiliares del facultativo. Y a este fin se llegó a la creación en 1928 de la enseñanza de auxiliares marroquíes de Medicina en la Facultad de Cádiz, estableciéndose, al año siguiente, becas especiales para los que deseaban cursarla. 
Diez años más tarde, en 1938, se creó en Tetuán la Escuela de Auxiliares Marroquíes de Medicina [24], que en años sucesivos fue concediendo los diplomas de sanitario.

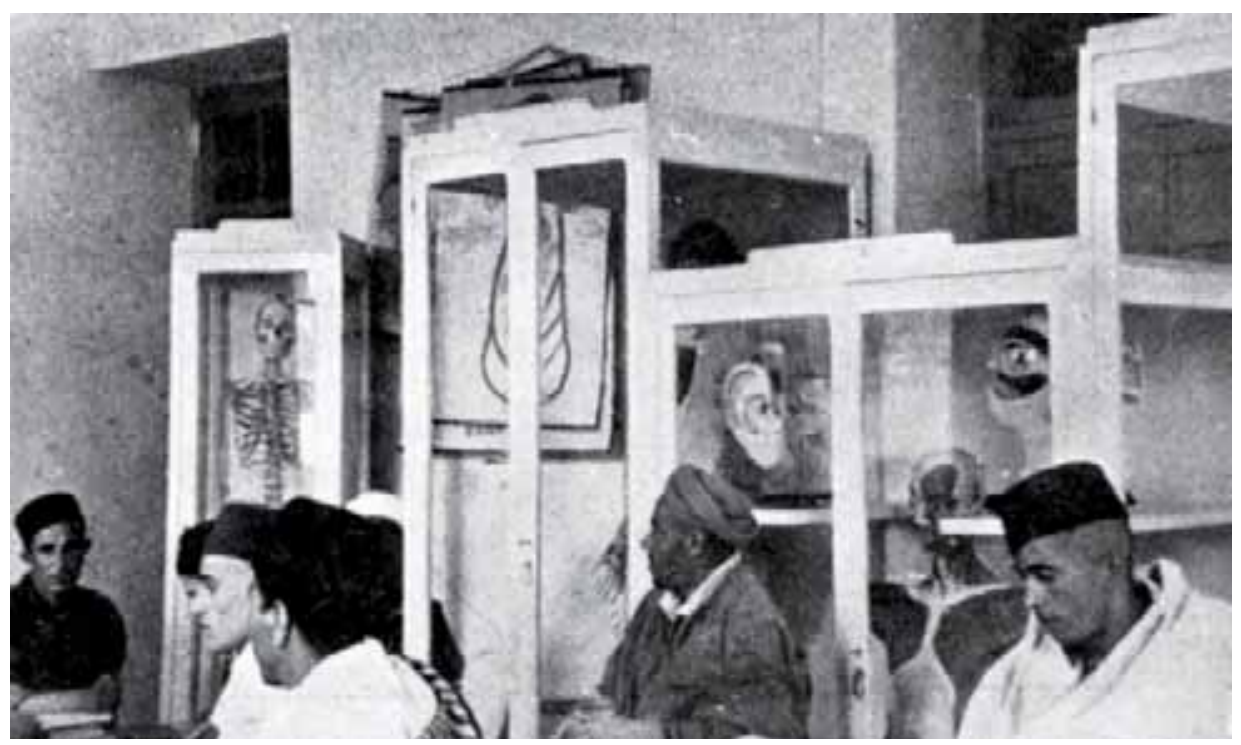

Fig.24. Escuela de formación de sanitarios marroquies en Tetuán.

Con la creación de la Escuela Politécnica [25], afecta a la Delegación de Educación y Cultura, en 1942 se establecieron varias carreras especiales para marroquíes de ambos sexos; entre ellas tres de Sanidad: Practicantes, Comadronas y Enfermeras Diplomadas.

Aparte de estas manifestaciones locales en la región, también en España han cursado carreras dentro del cuadro médico-sanitario muchísimos marroquíes, la mayoría como becarios de la Delegación de Educación y Cultura y de la de Asuntos Indígenas.

Uno de estos ejemplos lo constituye el Dr. Mohamed Ben-Alal El Uarty, de quién se dijo fue el primer médico bereber de Melilla y sus alrededores. Nacido en Melilla en al año 1912, tras cursar sus estudios de bachillerato, marcha a Madrid, donde se licencia y se especializa en Ginecología, acabando sus estudios universitarios en junio de 1936. Desgraciadamente su 
esperanzadora carrera se vio truncada al fallecer dos años más tarde. Sus restos descansan en el cementerio musulmán situado junto al Castillo de la Mota en Medina Sidonia.

Otro de estos ejemplos, lo constituye el caso del Dr. Ahmed Hach Aomar Ben Abdelallah [26] que, nacido en Farhana en 1914, cursó sus estudios de bachillerato en Melilla y posteriormente se licenció en Medicina por la Universidad Complutense de Madrid en 1941. Tras permanecer dos años como alumno del Dr. Jiménez Díaz, estuvo ejerciendo en pueblos cercanos a Melilla hasta 1950, marchando después a Tetuán. En 1956, tras la Independencia de Marruecos, es nombrado Delegado de Sanidad Pública en toda la zona norte del país.

Posteriormente ocupó diferentes cargos en el Ministerio de Sanidad marroquí; puestos como Director de la Lucha antituberculosa, Inspector General de Sanidad y Delegado de Sanidad en Tánger hasta 1971.

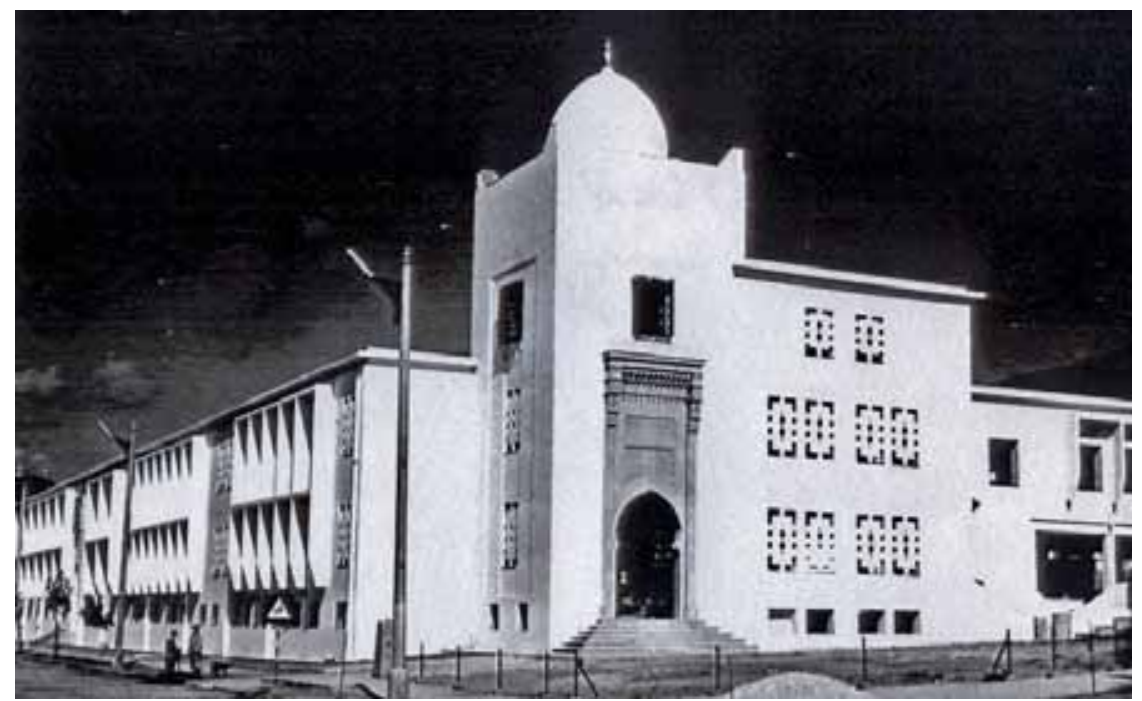

Fig.25. Escuela Politécnica de Tetuán.

\section{Conclusiones}

El Dr. Luis Herrero Muñoz decía, en la conferencia pronunciada en el salón de actos del Consejo Superior de Investigaciones Científicas el día 31 de enero de 1962, que "antes del Protectorado, hace ya siglos España prestaba la 
más humana de todas las ayuda; la sanitaria, poniendo en ello la abnegación que esta tarea merece".

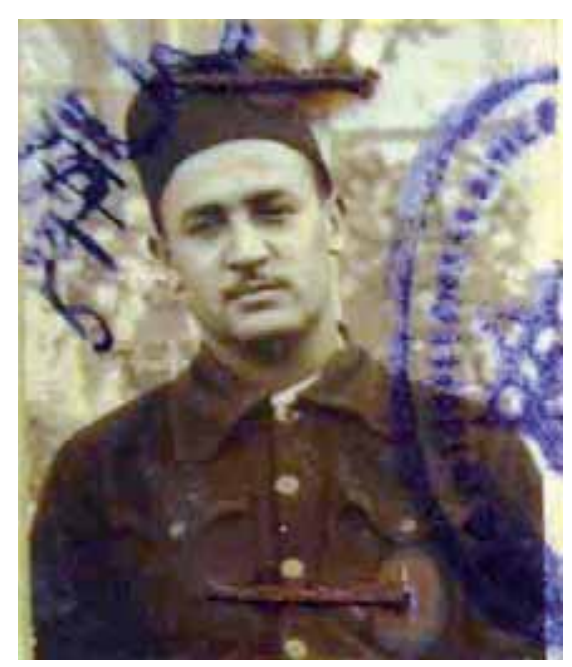

Fig. 26. Dr. Hach Aomar.

Así, recuerda que el 28 de junio de 1791, siendo comandante general de Ceuta Luis de Urbina y representante del Sultán en el territorio marroquí colindante su primo el Cherif Mulay Alí B. Ahmad B. Idris, pasa la frontera, a petición de éste, el doctor Hipólito Chenesi, médico militar de la guarnición de Ceuta, para efectuarle el tratamiento "de las continuas aprehensiones que tiene de su salud. Y sigue diciendo el Dr. Herrero Muñoz: "Pero ya con mucha anterioridad se venía prestando asistencia facultativa a todos aquellos que, demandándola, se dirigían desde el campo fronterizo al pie de la muralla y hospitalizando a aquellos que por su dolencia así lo necesitaran”. Otra referencia importante en este sentido, la hace Gabriel de Morales, en su trabajo Efemérides de la Historia de Melilla donde relata que en 1782, a instancias del alcaide Cador se atendió en el Hospital de Melilla a dos rifeños enfermos que marcharon curados 8 días después.

Queda claro pues que España ha prestado esta ayuda sanitaria a Marruecos antes, durante y después del Protectorado, pues a nadie se le escapa que aún se sigue atendiendo, en nuestro hospital, a un gran número de ciudadanos marroquíes que precisan asistencia médica. 
El hispanista tetuaní Mohammad Ben Azzuz, decía que el que desee enjuiciar y valorar imparcialmente la acción protectora de España en Marruecos debía tener en cuenta tres postulados:

1. En primer lugar, que el ejercicio de la verdadera acción protectora de España sólo pudo realizarse en un periodo de 28 años de duración, o sea desde el 10 de julio de 1927, en que los marroquíes depusieron las armas frente a la acción militar llamada de pacificación, hasta el 7 de abril de 1956, en que España reconoció la independencia de Marruecos, ya que durante el periodo comprendido entre 1912 y 1927, España tuvo que hacer frente a una formidable resistencia armada del pueblo marroquí en el norte, que rechazaba de plano el protectorado impuesto al país por el Tratado francomarroquí de 1912.

2. En segundo lugar, que la zona adjudicada a España en el convenio franco-español del 27 de noviembre de 1912 era parte integrante de lo que se ha dado en llamar el "Marruecos no útil". Se trataba de dos zonas: una situada al norte, la más belicosa del país, y otra al sur, totalmente desértica, y ambas eran terriblemente pobres.

3. Tercero: que España, a diferencia de Francia, sabía que tarde o temprano el Protectorado tendría su fin, y por eso la política practicada por ella en su Zona, no tendía a anular la identidad y los valores marroquíes; era una política fraternal, como correspondía a dos pueblos que han convivido juntos durante varios siglos de su historia. Prueba de ello es su política sumamente tolerante con el movimiento nacionalista, con las instituciones religiosas del país, con la lengua y la cultura, amén de los usos, costumbres y tradiciones.

Y como decía el Dr. Juan Solsona Conillera, Director de Sanidad e Higiene Públicas de las Zona del Protectorado Español en Marruecos: "Así fue como España, en unos pocos años, hizo pasar al norte de Marruecos de la era del maestro-sangrador, que perduraba allí desde hacía siglos, a la era del médico, propia de los países adelantados en los logros de la civilización.” 


\section{Bibliografía}

AZZUZ HAKIM. M. (1953). "La sanidad española en Marruecos”. Cuadernos de Estudios Africanos, $\mathrm{n}^{\mathrm{o}} 22$, p. 33-50.

BRAVO, J (1932). La medicina española y la medicina indígena en Marruecos. Imp., Enc., Lib. y Pap. La Industrial.

CASTRILlEJO PÉREZ, D. (2009). "Los consultorios de Nador y Zoco El Had en 1912 -

1913. Los inicios de la labor sanitaria española en esta zona de Marruecos”. Sanidad Militar, 65 (2), p. 132-143.

CORDERO TORRES, J.M. (1942). Organización del protectorado español en Marruecos. Tomo I y II. Madrid: Edit. Nacional.

CRENDE, J. (1923). Confidencias de un médico agareno: Cómo practican la medicina los Moros en el Siglo XX. Bilbao: Tip., Echeguren y Zulaica.

CRESPO REDODO, J. y col. (1944). Historia de Marruecos. Consejería de Educación, Embajada de España en Marruecos.

DELGADO, E. (1930). La sanidad en Marruecos. Información somera de cuanto ha hecho España en materia sanitaria. Alta Comisaría de España en Marruecos. Ceuta: Rev. África.

DÍAZ-PINES y FERNÁNDEZ-PACHECO, O (1953). Marruecos: El Protectorado español. Temas Españoles, $n^{\circ}$ 45. Prensa Gráfica, S.A.

GARCÍA FIGUERAS, T. (1945). España y su Protectorado en Marruecos (1912-1956). Nervio y perfil de una obra. Madrid, Instituto de Estudios Africanos.

GARCÍA FIGUERAS, T. (1947). España en Marruecos (la obra social). Madrid, Instituto de Estudios Africanos.

HERREO MUÑ̃Z, L. (1959). “Acción Sanitaria Española en Marruecos”. Archivos del Instituto de Estudios Africanos, 12, 57-93.

HERRERO MUÑNOZ, L. (1962). "La sanidad española en Marruecos”. Archivos del Instituto de Estudios Africanos, $\mathrm{n}^{\circ}$ 64, págs. 37-55.

IRIBARREN CUARTERO, I. (1942). Trabajos de un médico militar en el Rif (Beni Said). Ceuta, Imp. Imperio.

MARTÍN CORRALES, E. (1999). "El protectorado español en Marruecos (1912-1956)". En: Nogué, J. y Vilanova J.L. España en Marruecos (1912-1956) Discursos geográficos e Intervención territorial”. Lleida: Editorial Milenio.

MARTÍN CORRALES, E. (2002). 'Marruecos y el colonialismo español (1859-1912). De la guerra de África a la "penetración pacífica. Barcelona: Bellaterra.

MARTÍN CORRALES, E. (2007). "Marruecos y los marroquíes en la propaganda oficial del Protectorado (1912-1956)”. Mélanges de la Casa de Velázquez, nº 37-1, págs. 87107.

MARTÍNEZ ANTONIO, F.J (2004). "Medicina y sanidad en el protectorado de España en Marruecos. Resistencia, hibridación y transformación metropolitana”. La medicina ante el nuevo milenio: una perspectiva histórica, $X$, págs 381-394.

MORAlES LeZCANO, V. (1986). España y el Norte de África. El Protectorado en Marruecos (1912-1956). 2a ed., Madrid: UNED. 
PENNELL, C.R. (2001). La guerra del Rif. Abdelkrim El-Jattabi y su Estado rifeño. Melilla, UNED.

RAYNAUD, L. (1902). L'higiène et la médecine au Maroc. Alger : Imprimerie typographique et lithographique S. Lèon.

RIVET, D. (1988). Lyautey et línstitution du protectorar française au Maroc, 1912-1925. París: L'Harmatan.

SOLSONA CONILLERA, J. (1939). Breves notas sobre la Organización de los Servicios Sanitarios Oficiales en la Zona de Protectorado Español en Marruecos. Tetuán: Imp. Hispania

SOLSONA CONILLERA, J. (1941).

"Líneas generales de la organización y legislación de los Servicios Sanitarios en la Zona de Protectorado de España en Marruecos”. Boletín de Información estadística, demográfica y sanitaria, $\mathrm{n}^{\circ}$ mayo, 69-90.

SOLSONA CONILLERA, J. (1962). "Del maestro-sangrador al médico. El trabajo y la generosidad de España en la evolución sanitaria de Marruecos”, Archivos del Instituto de Estudios Africanos, ${ }^{\circ}$ 64, págs. 7-35.

TORRES ROLDÁN, A. (1937). La sanidad en el protectorado español en Marruecos. Ceuta: Imp. Imperio.

VALDÉS LAMBEA, J (1913). El dispensario indígena de Nador. $1^{a}$ memoria anual. Labor realizada y contribución al estudio de la Patología del Rif. Estadística. Melilla: Tipografía de la Gaceta.

VILLANOVA, J. L. (2004). El Protectorado español en Marruecos: organización política y territorial, Barcelona: Bellaterra.

VILlANOVA, J. L. (2010). "La organización territorial del Protectorado español en Marruecos". Reim, $\mathrm{n}^{\circ}$ 9, págs. 70-89

VILLANOVA, J.L. (2005). "Los interventores del Protectorado español en Marruecos (1912-1956) como agentes geopolíticos”. Ería, nº 66, págs. 93-111. 